\title{
MULTIFRACTAL CHARACTERISTICS OF CRITERIAAIR POLLUTANT TIME SERIES IN URBAN AREAS
}

\author{
Gordana Jovanović, ${ }^{12 *}$, \\ Svetlana Stanišić2 \\ Mirjana Perišić ${ }^{1,2}$ \\ ${ }^{1}$ Institute of Physics Belgrade, National \\ Institute of the Republic of Serbia, \\ University of Belgrade, \\ Belgrade, Serbia \\ ${ }^{2}$ Environment and Sustainable Development, \\ Singidunum University, \\ Belgrade, Serbia
}

\begin{abstract}
:
The complexity of spatial-temporal air pollutant concentration dynamics requires innovative modeling investigation approaches. The details of non-linear nature of pollutant behavior cannot be revealed by conventional approaches, but fractal and Hurst rescaled analyses allow the quantification of pollutant dynamics structure via self-similarity and scale invariance. In this study, we applied multiscale multifractal analysis (MMA) to investigate the complex time-series of criteria air pollutants $\left(\mathrm{PM}_{10}, \mathrm{PM}_{2.5}, \mathrm{NO}_{\mathrm{X}}, \mathrm{SO}_{2}, \mathrm{CO}\right.$ and $\mathrm{O}_{3}$ ). The results showed that $\mathrm{PM}_{10}$ and $\mathrm{PM}_{2.5}$ concentrations are more stable compared to gaseous oxides and exhibit less prominent multifractality. Out of gaseous contaminants, $\mathrm{CO}$ is confirmed to be less chemically reactive than $\mathrm{NO}, \mathrm{NO}_{2}, \mathrm{NO}_{x}, \mathrm{SO}_{2}$ and $\mathrm{O}_{3}$ under the same atmospheric conditions in urban and semi-urban area. As concluded, the multifractal analysis presented herein can enhance our understanding of specific pollutant dynamic features and support relevant sectors to control the pollutant release and distribution.
\end{abstract}

Keywords:

multiscale multifractal analysis (MMA), suspended particle matter (PM), criteria air pollutants, air pollution, urban environment.

\section{INTRODUCTION}

Air pollution poses a major threat to health and climate, and it has been estimated to become the leading cause of mortality worldwide by 2050 [1]. Seven million premature deaths every year occur as a result of stroke, cardiovascular and respiratory diseases, all of which can be related to detrimental effects of high air pollutant concentration exposure [2]. Although the contaminant emissions have been reduced, about $30 \%$ of citizens in European urban areas are still exposed to air pollutant levels that exceed EU air quality guidelines defined with the aim of health protection [3]. Therefore, the research of air pollutant spatial-temporal behavior in urban areas appears to be one with highest potential to contribute to society.

\author{
e-mail:
gjovanovic@singidunum.ac.rs \\ Correspondence: \\ Gordana Jovanović
}

Sinteza 2020

Sinteza 2020

submit your manuscript | sinteza.singidunum.ac.rs 
In the atmosphere, air pollutant lifetimes are in a range from hours to years, depending on air mass transport processes, undergoing transformations via chemical reactions and/or particle deposition. Although usually assumed to appear by a chance as a linear or a single-compartment processes, variations of air pollutant levels over time are neither simple nor random in their behavior. The factors like mutual pollutant interactions, meteorological parameters, and the emission source type and intensity, affect the air quality significantly and make the air pollutant temporal dynamics complex and difficult to analyze and understand.

The most striking feature of the pollutant concentration time-series refers to their long-term memory, which reflects how the pollutant past behavior patterns affects its future levels [4]. Self-similarity and scale-invariance are considered to be the memory characteristics of decisive importance concerning the pollutant time-series and therefore, vital for the estimation of long-range correlations and precise forecasting [5]. These structural properties can be captured by fractal and Hurst rescaled analyses that define fractals as self-similar shapes of the "structure holding the key to the whole structure" $[6,7,8]$. The multifractal approach has been applied for estimation of constitutional features and forecasting of air pollutant time-series $[9,10,11,12,13]$.

In this study, we focus on the investigation of timeseries of criteria air pollutants $\left(\mathrm{PM}_{10}, \mathrm{PM}_{2.5}, \mathrm{NO}_{\mathrm{x}}, \mathrm{SO}_{2}\right.$, $\mathrm{CO}$ and $\mathrm{O}_{3}$ ) across Belgrade with the aim to obtain more comprehensive understanding of the investigated species behavior and fate. Unlike the previous findings related to the Balkans, that were limited in terms of the result interpretations and sampling time, the findings presented herein are based on a long-term data and advanced investigation methods that enable pollutant temporal dynamics to be explored more profoundly.

\section{MATERIALS AND METHODS}

The data used for the analyses were obtained from the regular monitoring network of Institute of Public Health Belgrade and multi-year measurement campaign conducted from 2011 to 2016 at 9 sites covering $17 \mathrm{mu}-$ nicipalities located in Belgrade (Serbia) urban, semi-urban and rural areas. The dataset comprised the concentrations of inorganic gaseous pollutants $\left(\mathrm{CO}, \mathrm{SO}_{2}, \mathrm{NO}\right.$, $\mathrm{NO}_{2}, \mathrm{NO}_{\mathrm{x}}$ and tropospheric $\mathrm{O}_{3}$ ) and particulate matter (PM10 and PM2.5) registered at the following locations: four of urban-traffic type (Institute of Public Health - IPB, New Belgrade - NBG, Zemun - ZEM and Slavija - SLA), two of urban-industry type (Obrenovac - OBR and Lazarevac - LAZ), one suburban location (Ovča - OVC), and two locations classified as rural-industry sites (Grabovac - GRA and Veliki Crljeni - VC).

We applied multiscale multifractal analysis (MMA) [13] to investigate fractal characteristics of complex $\mathrm{PM}_{10}, \mathrm{PM}_{2.5}, \mathrm{NO}_{\mathrm{x}}, \mathrm{SO}_{2}, \mathrm{CO}$ and $\mathrm{O}_{3}$ time series. MMA is a generalization of the standard MF-DFA, which adds the dependence on scale, providing a broader analysis of the fluctuation properties, as well as more general and stable results [14].

The aim of this study was to investigate the pollutant timeseries, as described below. We delineated the strength of multifractality by the multifractal singularity, Q. The bigger the $\mathrm{Q}$ is, the more pollutant concentration timeseries is influenced by $Q$ interval fluctuations in negative or positive direction, while the absence of fluctuations results in $\mathrm{Q}$ equals to 0 and represents a mono-fractal behavior [10]. In addition, the span of multifractal singularity $\left(\Delta \alpha=\alpha_{\max }-\alpha_{\min }\right)$ is an alternative way to study the strength of multifractality; the bigger $\Delta \alpha$ is, the stronger the multifractality degree is [5].

Besides, we considered Hurst exponent $(\mathrm{H})$ which indicates the persistence level of the pollutant concentration time series denoted by the following values $[5,15,16]$ :

- $\mathrm{H} \geq 1.5$ represents brown noise uncorrelated processes with infinite memory;

- $\mathrm{H}=1$ refers to pink noise, i.e. the most prominent, stable and adaptable fractal phenomena with long-term memory;

- $0.5<\mathrm{H}<1.5$ describe random walk processes with long-range correlated and persistent structure;

- $\mathrm{H}=0.5$ refers to white noise involving uncorrelated random variables with no memory;

- $\mathrm{H}<0.5$ is associated with the anti-persistent increments which possess anti-correlated structure.

\section{RESULTS AND DISCUSSION}

In general, a sharp negative slope of $H$ versus $Q$ surfaces clearly shows the multifractal behavior of all examined pollutant concentrations, which is opposite to the straight line with zero gradient, being an indicator of monofractal systems [15]. The $\mathrm{H}$ values above 0.5 suggest nonrandom pollutant fluctuations over time and reflect non-stationary signals with long-range dependent structure, which follow a power law. 
The very few cases of $\mathrm{H}<5$, which indicate oscillating processes have occurred only at $\mathrm{Q}=5$ for: $\mathrm{O}_{3}$ being measured at urban-traffic and urban-industry sampling sites (NBG and LAZ), at scales between 50 and 130 hours; $\mathrm{NO}$ and $\mathrm{NO}_{\mathrm{x}}$ registered at urban-ZEM location between 30 and 140 hours, and $\mathrm{SO}_{2}$ being registered at urban and rural locations (OBR and GRA) impacted by the coal-fired power station emissions between 200 and 360 hours. Discrepancies in $\mathrm{SO}_{2}$ dynamics in rural area could be attributed to intermittent pollution accidents related to the emissions from industrial sources and strong wind events. More comprehensive evaluation of $\mathrm{O}_{3}$ and $\mathrm{NO}_{\mathrm{x}}$ pathways in near-ground atmosphere, as well as the analysis of noted concentration deviations, would require more detailed investigation on volatile organic compounds (VOCs) and their interactions with NOX and $\mathrm{O}_{3}$. Unlike many pollutants, ground-level $\mathrm{O}_{3}$ is a product of photolytic decomposition of precursors rather than a component of primary emissions. Generation and removal of $\mathrm{O}_{3}$ is strongly affected by the presence of $\mathrm{NO}_{x^{\prime}}$, their type, lifetime and the way they interact with VOC, $\mathrm{HO} \cdot$ and ROO - in a cycle of catalytic reactions. The interactions are impacted by location-specific factors, including pollutant sources and meteorological parameters.

As far as individual pollutants are concerned, $\mathrm{H}$ values between 0.70 and 1.5 showed the long-range persistent PM10 time-series at almost all sampling sites (Fig. 1). The most prominent variations of $\mathrm{H}$ values were apparent at lower and upper $\mathrm{Q}$ boundaries $(-5,5)$ exhibiting maximums at the small scales and in the scale range between 100 and 200 hours. Since $\mathrm{PM}_{10}$ represents a mixture of microscopic solid and liquid suspended matters involved in inherent condensation and nucleation, the registered cross-correlation behavior of meteorological factors and $\mathrm{PM}_{10}$ was not observed in the case of meteorological factors and the investigated gases [10, 17]. Hurst exponent exceeded 1.5 only at rural GRA and suburban OVC sampling sites, indicating pollutant concentration patterns which can be referred to a brown noise. These behavior pattern appeared at small temporal scales, up to 60 hours, and in the domain of negative $Q$ values implying that the $\mathrm{PM}_{10}$ segments are more prone to small and large spatial-temporal variations. Air quality in rural areas being dominated by industrial emissions is more sensitive to fluctuations of meteorological factors compared to air quality in urban sites which is mainly burdened by alternating traffic emissions. After reached Brownian increments, the extremely steep slopes of $\mathrm{H}$ versus $\mathrm{Q}$ surfaces characterized the $\mathrm{PM}_{10}$ concentration behavior patterns at a time scale of up to 150 hours.
The results suggest a strong multifractal nature of $\mathrm{PM}_{10}$ which weakened over time and approached to the "healthy complex system" of pink noise.

Time-series of $\mathrm{PM}_{2.5}$ were investigated at different sites, suburban OVC in residence area influenced by domestic heating, and VEL rural site in in the coal mining industrial area. Strong multifractal nature of $\mathrm{PM}_{2.5}$ referring to persistence and long-range correlations, was apparent in the scale range between 30 and 150 hours, as well as in the range between the 30 and 90 hours at OVC and VEL, respectively (Fig. 2). While multifractal features of $\mathrm{PM}_{2.5}$ trend decayed with time, they were maintained in the area of negative $\mathrm{Q}$ domains.

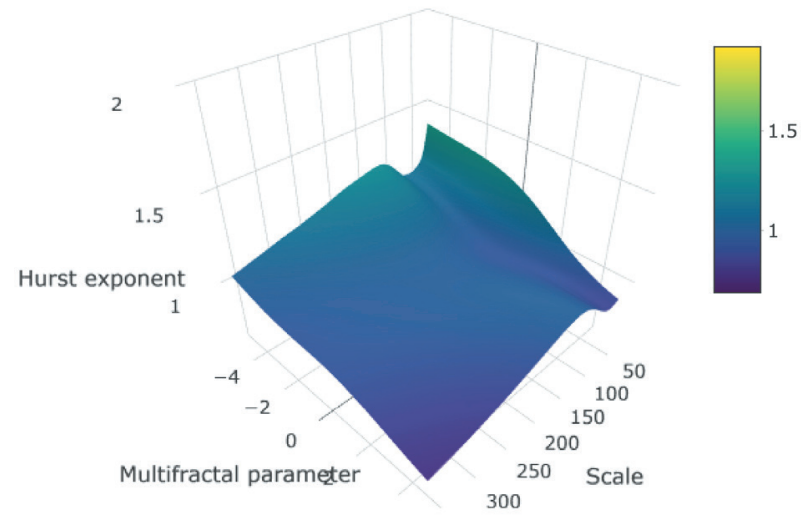

Fig. 1. MMA-derived Hurst surfaces for $\mathrm{PM}_{10}$ sampled at typical urban location in the Belgrade centre.

However, at a time scale from the 150 to 360 hours $\mathrm{PM}_{2.5}$ concentration behavior patterns were different for $\mathrm{Q}>0$, reflecting the probable mono-fractal characteristics. $\mathrm{PM}_{2.5}$ and $\mathrm{PM}_{10}$ multifractal patterns resemble for $\mathrm{Q}$ interval between 0 and 5 , which illustrates their monofractal nature, whereas differences in their behavior are reflected in the $\mathrm{Q}$ interval between -5 and 0 , which supports previous findings on dissimilarities among differently sized PMs in urban areas [18]. A strong multifractal behavior of PM sized below $5 \mu \mathrm{m}$, and a weak and/or monofractal stochastic behavior of $\mathrm{PM}>5 \mu \mathrm{m}$ was pronounced. In addition, the generalized distance coefficient (0.069), which was above threshold value of 0.065 , indicated that the $\mathrm{PM}_{2.5}$ and $\mathrm{PM}_{10}$ time-series are statistically different.

Multiscale multifractal analysis of $\mathrm{SO}_{2}$ concentrations showed highly distinctive patterns depending on the sampling site (Fig. 3). The absolute similarities in the pollutant time-series between different sampling sites could not be expected due to numerous emission 
sources, chemical reactions and meteorology, which are location-specific. Correspondingly to the findings for $\mathrm{PM}_{10}$, the highest $\mathrm{H}$ values (from 1.64 at IPH to 2.37 at OBR) were observed at small time scales ranging from the 30 and 100 hours and in the area of $Q$ negative domains (from -5 to -1 ).

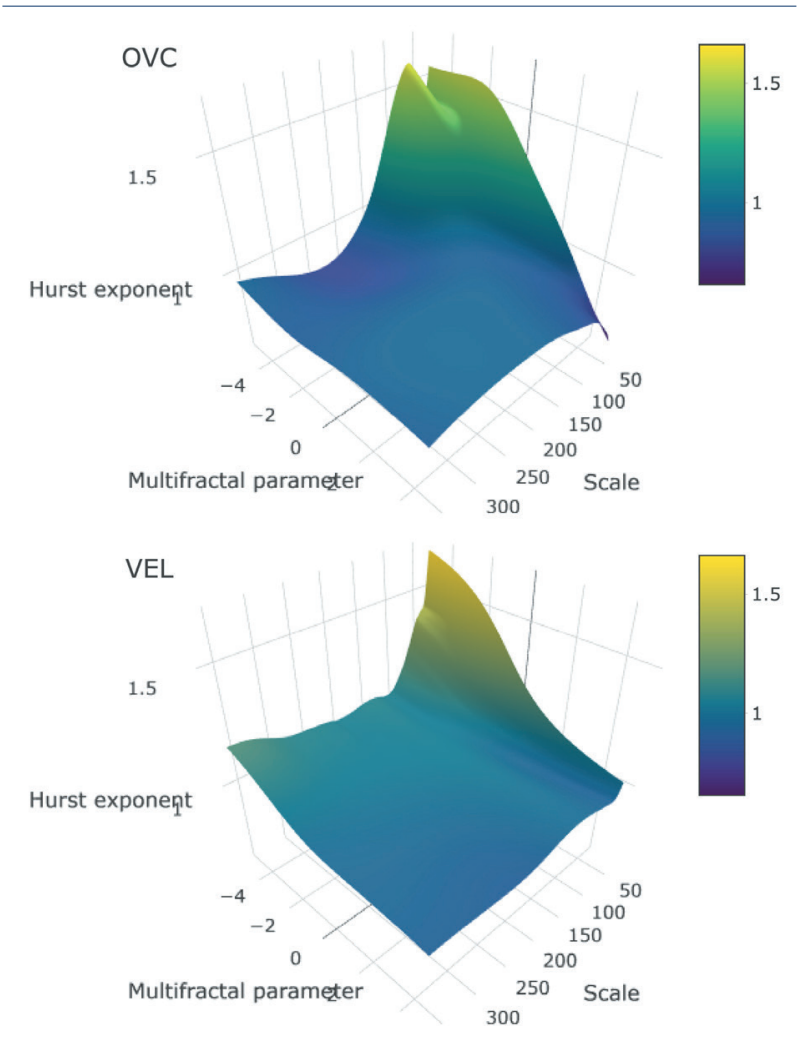

Fig. 2. MMA-derived Hurst surfaces for $\mathrm{PM}_{2.5}$ sampled at two rural/semi-urban sites in Belgrade.

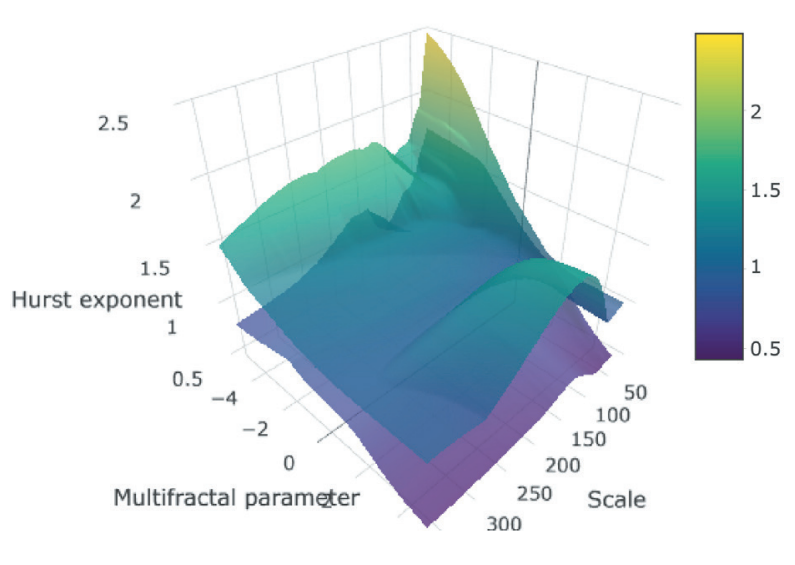

Fig. 3. MMA derived Hurst surfaces for $\mathrm{SO}_{2}$ in Belgrade.
Such high $\mathrm{H}$ maximums induced steeper slopes of $H$ versus $Q$ surfaces implying unequivocal multifractality of $\mathrm{SO}_{2}$ time-series. In addition, the results suggest that random fluctuations of $\mathrm{SO}_{2}$ do not dissipate over time and possess brown-noise infinite memory. However, the most dominant characteristics of the $\mathrm{SO}_{2}$ concentration behavior pattern are a long-range correlated structure and fast evolving fluctuations $(\mathrm{H}<1)$. Influence of $\mathrm{PM}_{10}$ presence and potential $\mathrm{SO} 2$ adsorption is a possible cause of $\mathrm{SO}_{2}$ level variability, and therefore, multifractality. The studies aimed at chemical composition analysis identified material containing inorganic/black carbon and $\mathrm{SO}_{2}$ as key constituents of $\mathrm{PM}_{10}$ and $\mathrm{PM}_{2.5}[19,20]$.

The time-series of nitrogen oxides ( $\mathrm{NO}, \mathrm{NO}_{2}$ and $\mathrm{NO}_{\mathrm{x}}$ ) resemble each other at almost all sampling sites confirming the same origin and interrelations between these compounds (Fig. 4). Contrary to the $\mathrm{PM}_{10}$ and $\mathrm{SO}_{2}$ segments, $\mathrm{H}$ value reached plateau-shaped maximums higher than 1.5 at a larger scale from the 150 to 360 hours in the negative domains of Q interval (small fluctuations between -5 and $\approx-2$ ). However, the dominant $\mathrm{H}$ values $(0.5-1.5)$ reflect persistent/stable pollutant concentration behavior patterns and this trend is likely to be maintained over time. Chemical reactions with $\mathrm{O}_{3}$ and volatile precursors in which nitrogen oxides are involved provide a possible explanation for the strong multifractality of $\mathrm{NO}, \mathrm{NO}_{2}$ and $\mathrm{NO}_{x}$. The exceptions from described phenomenon are behavior patterns of $\mathrm{NO}, \mathrm{NO}_{2}$ and $\mathrm{NO}_{\mathrm{x}}$ levels registered at two urban sites - SLA and LAZ.

In contrast to the other gaseous pollutants, $\mathrm{CO}$ showed less pronounced multifractality (Fig. 5) in urban areas. The highest peaks were observed at the time scale of 30 hours, and $\mathrm{H}$ exceeded 1.5 only between the 30 and 40 hours at an urban site - IPH. However, the multifractality in CO level behavior patterns weakened in the area of large fluctuations corresponding to positive Q domains approaching mono-fractal behavior between 100 and 360 hours, which reflects the stability of CO compared to $\mathrm{NO}, \mathrm{NO}_{2}, \mathrm{NO}_{\mathrm{x}}$ and $\mathrm{SO}_{2}$. 


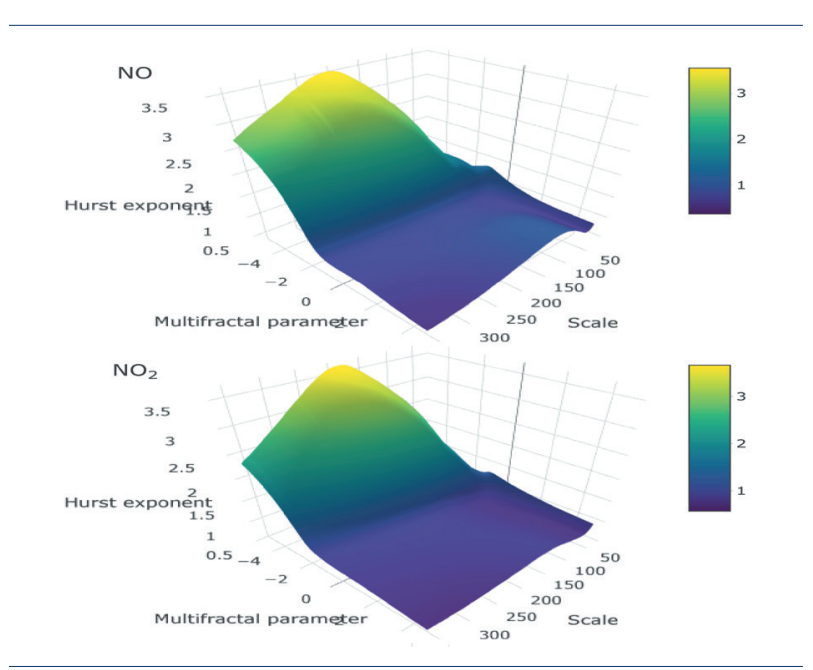

Fig. 4. MMA-derived Hurst surfaces for nitrogen oxides (IPH).

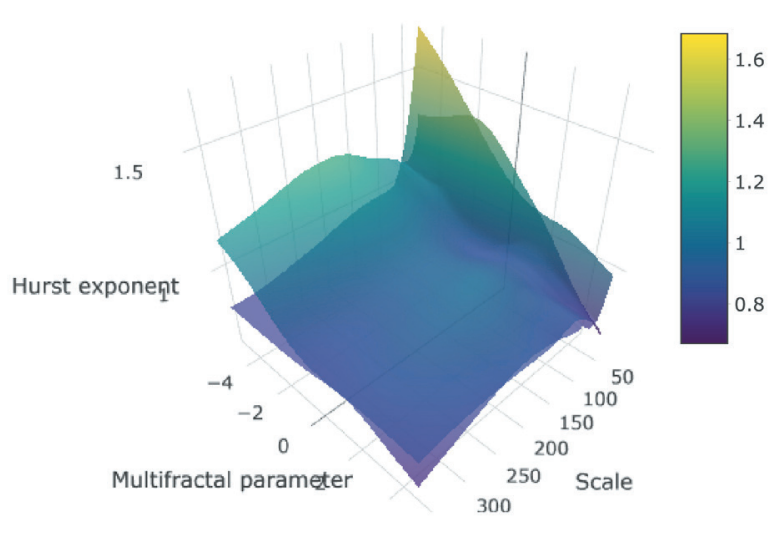

Fig. 5. MMA derived Hurst surfaces for CO in Belgrade.

\section{CONCLUSION}

The behavior of suspended particles $\left(\mathrm{PM}_{10}\right.$ and $\left.\mathrm{PM}_{2.5}\right)$ appeared to be more consistent in nature and exhibit less prominent multifractality than gaseous pollutants which is expected concerning the chemical reactivity of $\mathrm{NO}$, $\mathrm{NO}_{2}, \mathrm{NO}_{\mathrm{x}}$, and $\mathrm{SO}_{2}$. Long-range correlated structure of $\mathrm{PM}_{10}$ time-series is likely to be driven by the variability of meteorological factors, while the corresponding patterns of $\mathrm{SO}_{2}$ and nitrogen oxides could be a consequence of accidental pollution episodes and chemical reactions. Bearing upon the previously described complexity of the parameters affecting pollutant time-series, we emphasize that discussion above could not be used as a definite source of information regarding the pollutant behavior. However, what is of outmost importance is that given results are not biased by mean pollutant concentrations and may be regarded as representative for the studied area. For this reason, the study could serve as a standpoint to evaluate pollutant predictability over urban/rural areas based on the pollutant multifractal nature. Beside commonly used methods of statistical analysis and source apportionment, the multifractal analysis presented herein could reveal specific pollutant pathways and support relevant economy and governmental sectors to control the pollutant release and distribution.

\section{ACKNOWLEDGMENT}

The authors acknowledge funding provided by the Science Fund of the Republic of Serbia \#GRANT No. 6524105, AI - ATLAS.

\section{REFERENCES}

[1] Organization for Economic Co-Operation and Development (OECD) Environmental Outlook to 2050: The Consequences of Inaction. Organization for Economic Co-Operation and Development (OECD); Paris, France: 2012.

[2] WHO, https://www.who.int/health-topics/airpollution\#tab=tab_1

[3] European Environment Agency (EEA) Air Quality in Europe-2017 Report EEA Report No 13/2017. European Environment Agency (EEA); Copenhagen, Denmark: 2017

[4] A. Chelani, "Long-memory property in air pollutant concentrations." Atmos. Res. 2016, pp. 1-4.

[5] T. Stadnitski, "Measuring fractality." Front. Physiol. 2012, pp. 1-13.

[6] H.E. Hurst, "Long-term storage capacity of reservoirs." Transactions of the American Society of Civil Engineers 1951, pp 770-799.

[7] B.B. Mandelbrot, J.R. Wallis, "Robustness of the rescaled range $R / S$ in the measurement of noncyclic long-run statistical dependence." Water Resour. Res. 1969, pp. 967-988.

[8] BB. Mandelbrot, "The Fractal Geometry of Nature." New York: W.H. Freeman, 1977.

[9] Q. Dong, Y. Wang, P. Li, "Multifractal behavior of an air pollutant time series and the relevance to the predictability.” Environ. Pollut. 2017, pp. 444-457.

[10] H.d, He, "Multifractal analysis of interactive patterns between meteorological factors and pollutants in urban and rural areas." Atmos. Environ. 2017, pp. 47-54. 
[11] T. Plocoste, R. Calif, S. Jacoby-Koaly, “Temporal multiscaling characteristics of particulate matter PM10 and ground-level ozone $\mathrm{O} 3$ concentrations in Caribbean region." Atmos. Environ. 2017, pp. 22-35.

[12] A. Stojić, S. Stanišić Stojić, I. Reljin, M. Čabarkapa, A. Šoštarić, M. Perišić, Z. Mijić, "Comprehensive analysis of PM10 in Belgrade urban area on the basis of long-term measurements." Environ. Sci. Pollut. Res., 2016, pp. 10722-10732.

[13] A. Stojić, S. Stanišíć Stojić, M. Perišić, Z. Mijić, "Multiscale multifractal analysis of nonlinearity in particulate matter time series." Paper presented at the sixth international WeBIOPATR workshop and conference, Serbia, Belgrade, September 6-8, 2017.

[14] J. Gierałtowski, J.J. Żebrowski, R. Baranowski, "Multiscale multifractal analysis of heart rate variability recordings with a large number of occurrences of arrhythmia." Phys. Rev. 2012, p. 021915.

[15] E.A.F. Ihlen, "Introduction to multifractal detrended fluctuation analysis in Matlab." Front. Physiol. 2012, pp. 1-18.
[16] E. Molino-Minero-Re, F. García-Nocetti, H. BenítezPérez, "Application of a Time-Scale Local Hurst Exponent analysis to time series." Digit. Signal Process. 2015, pp. 92-99.

[17] C. Zhang, Z.W. Ni, L.P. Ni, "Multifractal detrended cross-correlation analysis between PM2.5 and meteorological factors." Physica A 2015, pp. 114-123.

[18] Y. Xue, W. Pan, W.Z. Lu, H.D. He, "Multifractal nature of particulate matters (PMs) in Hong Kong urban air." Sci. Total Environ. 2015, pp. 744-751.

[19] N.P. Ivleva, U. McKeon, R. Niessner, U. Pösch, "Raman Microspectroscopic Analysis of Size-Resolved Atmospheric Aerosol Particle Samples Collected with an ELPI: Soot, Humic-Like Substances, and Inorganic Compounds.” Aerosol Sci. Tech. 2007, pp. 655-671.

[20] U. Pöschl, "Atmospheric Aerosols: Composition, Transformation, Climate and Health Effects." Angewandte Chemie 2005, pp. 7520-7540. 